\title{
CLASPS IN REMOVABLE ORTHODONTICS
}

\author{
Mustapha Mansuri, Varun Pratap Singh
}

\begin{abstract}
The success of removable orthodontic appliance mainly depends upon good retention of the appliance. Adequate retention of a removable orthodontic appliance is achieved by incorporating certain wire components, called clasp, which engages the undercuts on the teeth. Clasps are the retentive components of removable orthodontic appliances. There are various designs of clasps advocated for various clinical situations. This article presents an overview of various clasp designs with advantages and disadvantages of each type and their uses in particular clinical situations.
\end{abstract}

Key words: Clasp, Removable orthodontic appliance, Retention.

\section{Introduction}

Clasps are wire components that aid in retention of a removable appliance ${ }^{[1]}$ These are the retentive components that aid in keeping the appliance in place and resist displacement of the appliance.

\section{Mode of action}

Clasps act by engaging constricted areas of the teeth, called undercuts. There are two types of undercuts found in natural dentition.

1. Buccal and Lingual cervical undercuts

2. Mesial and Distal proximal undercuts The mesial and distal undercuts of the teeth begin below the contact points. ${ }^{[2]}$ These undercuts are accessible very soon after a tooth has erupted. The buccal and lingual undercuts are much less extensive and are not accessible until the teeth are fully erupted. Thus, a clasp that makes use of mesial and distal undercuts is more useful and more efficient than a clasp which makes use of buccal and lingual undercuts.

An ideal clasp should ${ }^{[1]}$ :-

- Offer adequate retention
- Permit usage in both fully and partially erupted teeth

- Be passive

- Be easy to fabricate

- Not impinge on the soft tissue

- Not interfere with normal occlusion

\section{Different clasps are ${ }^{[1][3]}$}

1. 'C' clasp

2. Jackson's clasp

3. Arrowhead clasp

4. Adam's clasp

5. Delta clasp

6. Southend clasp

7. Triangular clasp

8. Ball-end clasp

9. Double ball-end clasp

10. Schwarz clasp

11. Crozat clasp

12. Duyzing clasp

13. Eyelet clasp

14. Plint clasp

15. Visick clasp

\section{1. 'C' clasp}

It is also known as three-quarter clasp (3/4 clasp) or Circumferential clasp. They are very simple clasp and engage bucco-cervical undercut. 


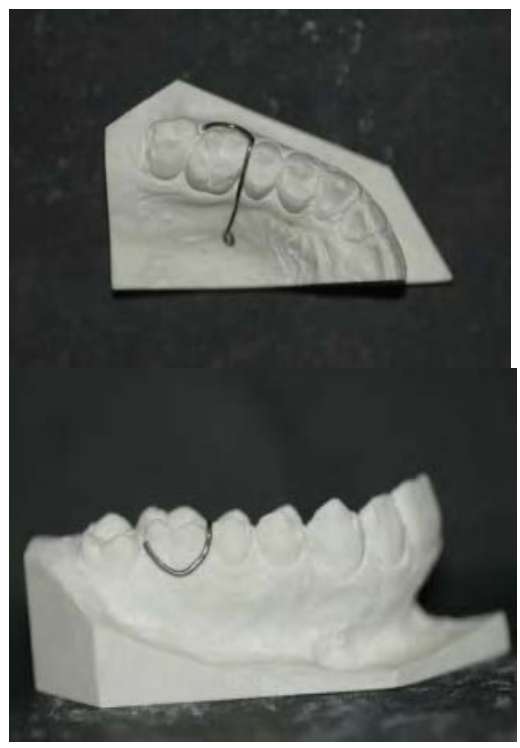

Fig. Circumferential Clasp

Advantages:-

- Easy to construct

- Simple design

- Prevent mesial migration of tooth Disadvantage:-

- It can't be used in partially erupted teeth.

\section{Jackson's clasp}

It is also known as Full clasp or ' $U$ ' clasp. It was introduced by V H Jackson in 1906. This clasp makes use of bucco-cervical undercut and also the mesial and distal proximal undercuts.

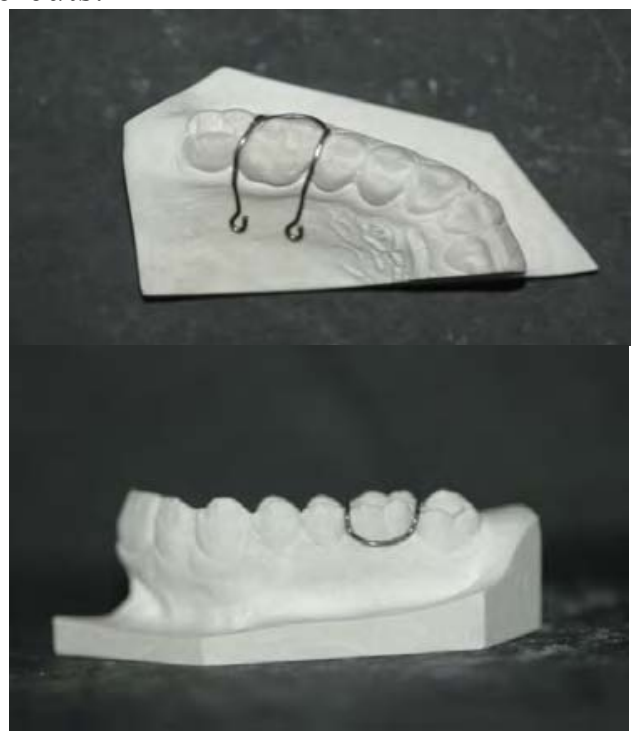

Fig. Jackson's clasp
Advantages:-

- Simple to construct

- Offers adequate retention

Disadvantage:-

- Inadequate retention in partially erupted teeth.

\section{Arrowhead Clasp}

This clasp was introduced by A M Schwarz in 1956. This clasp makes use of mesial and distal undercuts. This clasp is made using half round or round stainless steel wire of $0.7 \mathrm{~mm}$ diameter. This clasp is made by use of a special plier called 'Tischler's plier'.
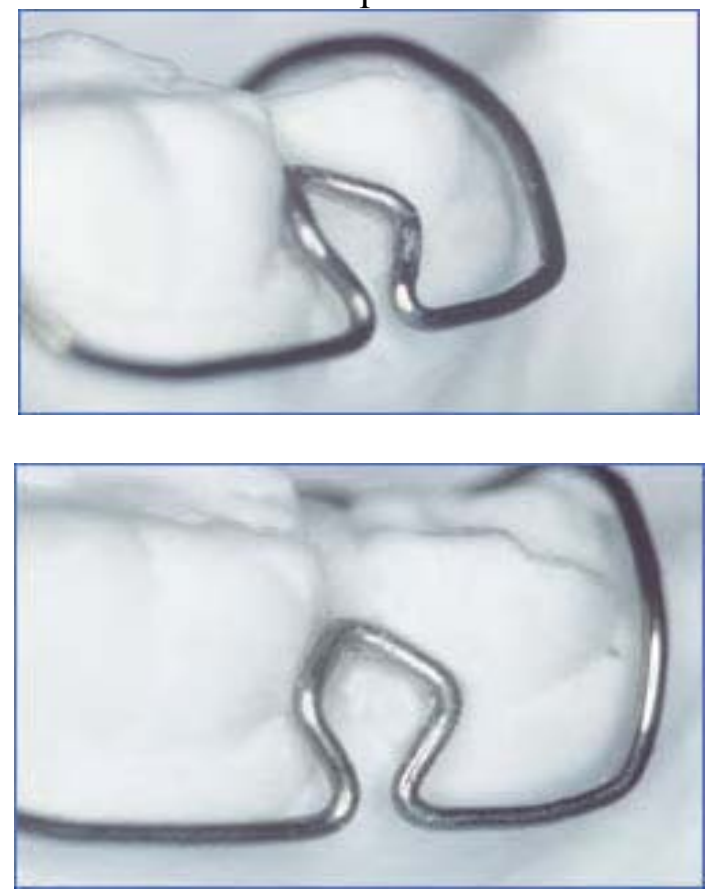

Fig. Arrowhead clasp

Advantages:-

- Good retention on partially erupted tooth

- Eruption of tooth is not hampered

Disadvantages:-

- Occupies large amount of buccal surface

- Requires special plier and adequate skill for construction.

\section{Continuous Arrowhead clasp}

This clasp carries 4-6 arrow clasps. It is one continuous wire with ends in acrylic mass. 


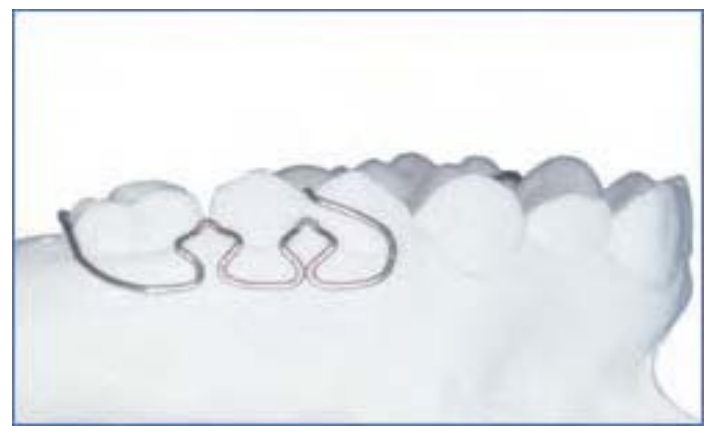

Fig. Continuous arrowhead clasp

\section{Adam's clasp}

It is also known as Universal clasp or Modified arrowhead clasp or Liverpool clasp. This clasp was devised by C P Adam in 1948. This clasp makes use of mesial and distal undercuts. This is the most effective and most widely used orthodontic clasp today. This clasp is constructed using $0.7 \mathrm{~mm}$ hard round stainless steel wire.
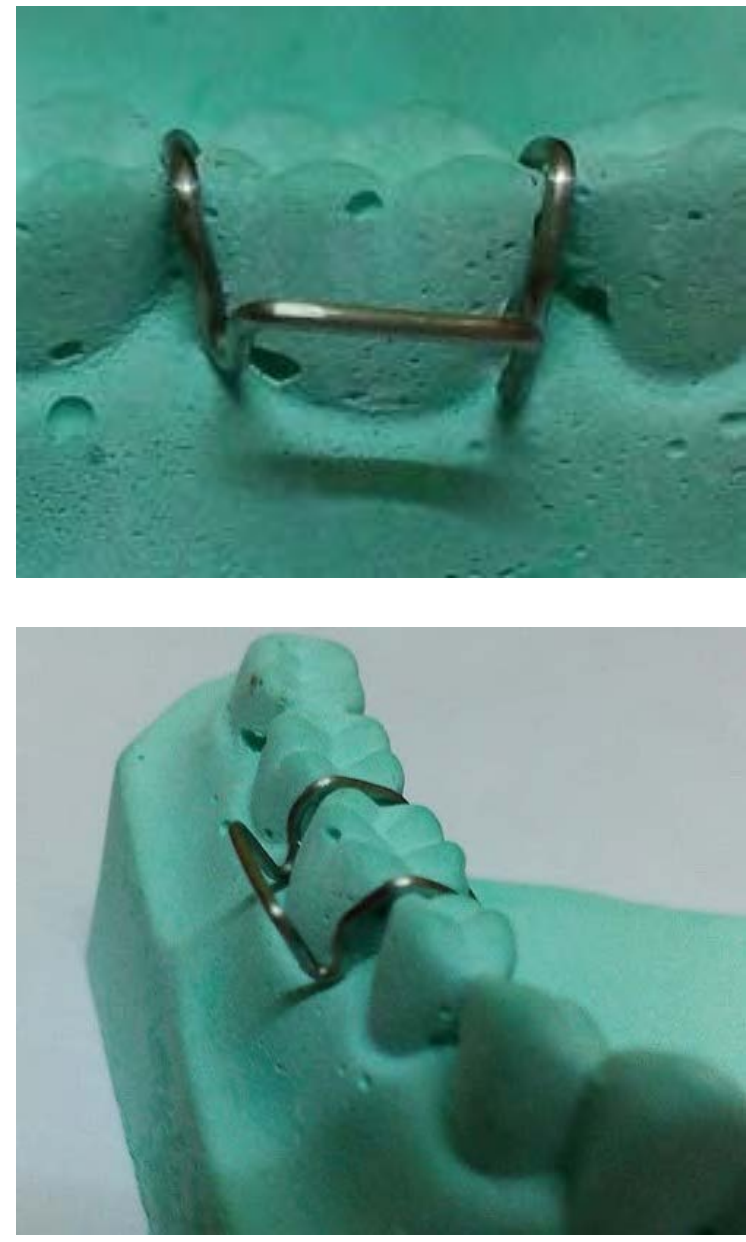

Fig. Adam’s clasp
Advantages:-

- This clasp is strong, simple and easily constructed.

- It can be used on any tooth (deciduous or permanent, partially or fully erupted, incisors or premolars or molars).

- It is comfortable to wear and resistant to breakage.

- It is small and occupies minimum space.

- It can be modified in a number of ways.

- No specialized instrument is needed for construction of clasp. Routinely used Young's Universal plier or Adam's plier can be used.

Parts of Adam's clasp

- Two arrowheads

- Bridge

- Two retentive arms

Bridge- It should be straight and midway between the occlusal surface and gingival margin. It should be $2 \mathrm{~mm}$ away from the tooth surface and parallel to it. When viewed from the side, the bridge should be at $45^{\circ}$ angle to tooth surface.

Arrowheads- should be parallel to each other and should sit in the mesial and distal undercuts.

Retentive arms- continue on the lingual or palatal surface that get embedded into the acrylic.

\section{Modifications of Adam's clasp}

4.1 Adam's clasp with single arrowhead

4.2 Adam's clasp with J hook

4.3 Adam's clasp with incorporated helix

4.4 Adam's clasp with additional arrowhead

4.5 Adam's clasp with soldered buccal tube

4.6 Adam's clasp with distal extension

4.7 Adam's clasp on incisors and premolars

4.8 Smart clasp:- A modified Adam's clasp 


\subsection{Adam's clasp with single arrowhead} This clasp consists of only single arrowhead instead of two arrowheads. This clasp combines characteristics of Adam's clasp and ' $\mathrm{C}$ ' clasp. It is indicated in partially erupted tooth where the single arrowhead engages the mesial undercut and the bridge is modified to encircle the tooth distally. The partially erupted tooth is usually the last erupted molar.

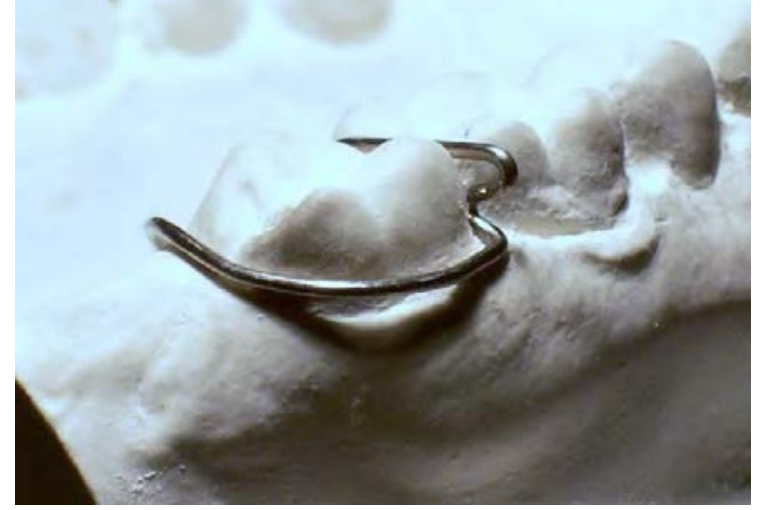

Fig. Adam's clasp with single arrowhead

\subsection{Adam's clasp with $\mathrm{J}$ hook}

A ' $\mathrm{J}$ ' shaped hook is soldered to the bridge of the Adam's clasp directed gingivally with the hook pointed distally. This hook is used to engage elastics.

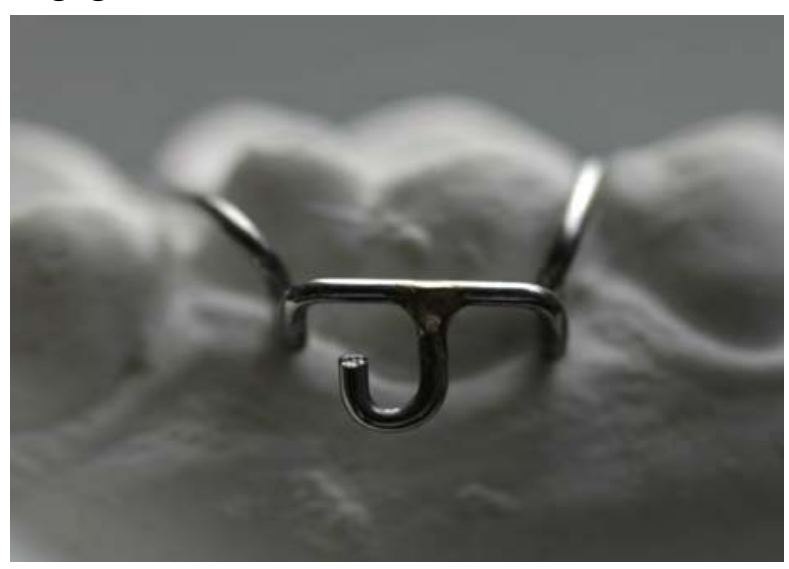

Fig. Adam's clasp with J hook

\subsection{Adam's clasp with incorporated helix}

A helix is incorporated into the bridge of the Adam's clasp. This is also useful in engaging elastics. This modification is preferred on mandibular molars.

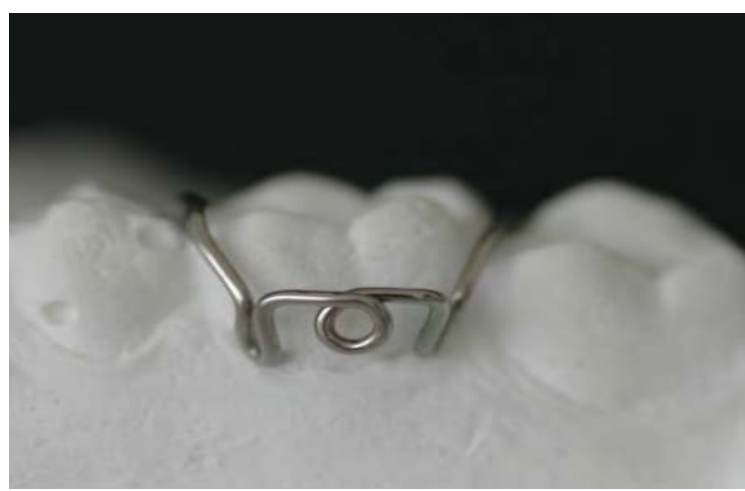

Fig.Adam's clasp with incorporated helix

\subsection{Adam's clasp with additional arrowhead}

An additional arrowhead is soldered onto the bridge of the Adam's clasp. This clasp is used when additional retention is required. The additional arrowhead fits to the undercut of adjacent tooth.

Fig. Adam's clasp with additional arrowhead

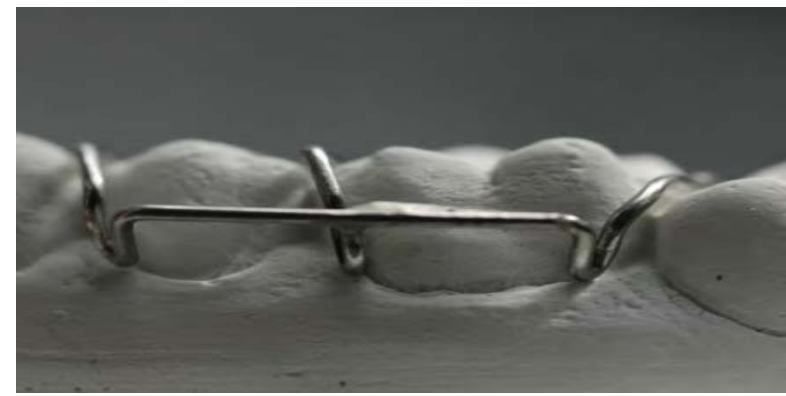

\subsection{Adam's clasp with soldered buccal tube} Attachment of buccal tube to Adam's clasp was described by J C Stephenson. A buccal tube is soldered onto the bridge of the Adam's clasp. This modification is used when an extraoral anchorage is needed using headgear or other assembly.

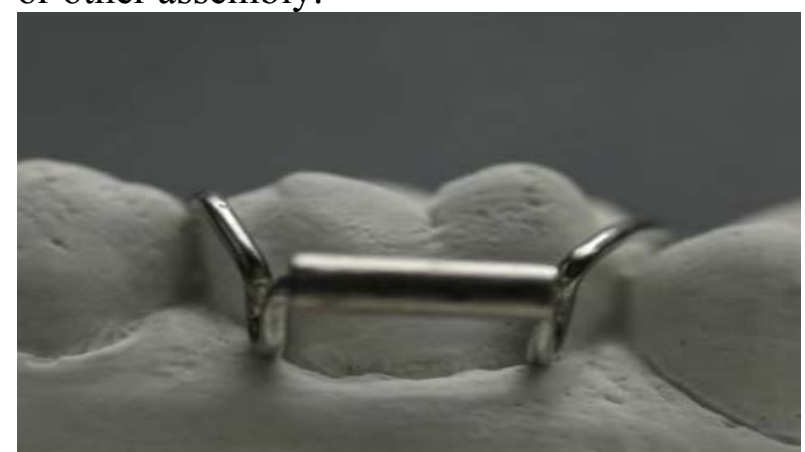

Fig. Adam's clasp with soldered buccal tube 


\subsection{Adam's clasp with distal extension} A small extension is incorporated distally in the distal arrowhead. This distal extension helps to engage elastics.

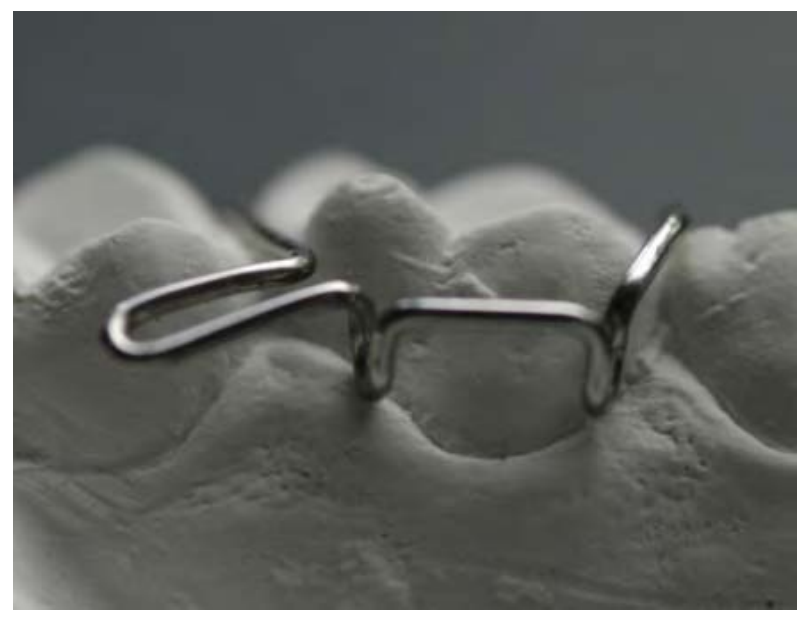

Fig. Adam's clasp with distal extension

4.7 Adam's clasp on incisors and premolars This clasp is fabricated on incisors and premolars when retention is required in those areas. This clasp can be constructed in such a way that it can span a single tooth or two teeth.

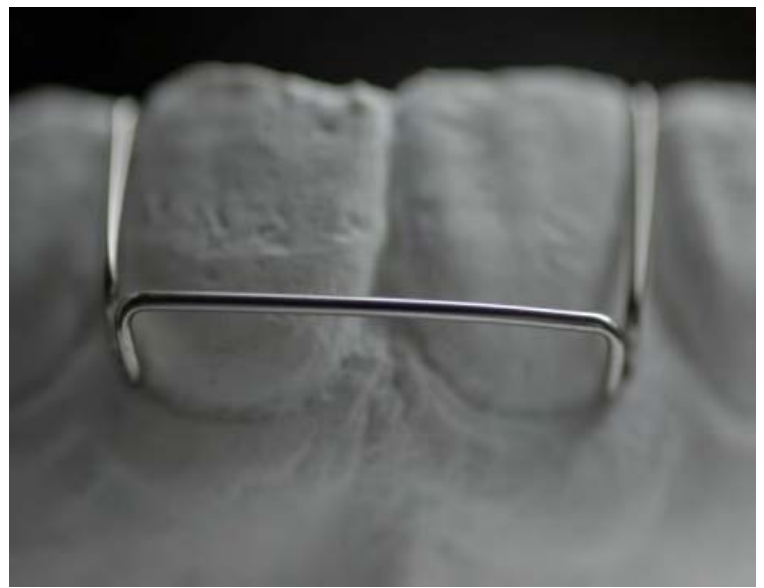

Fig. Adam's clasp on incisors

4.8 Smart Clasp: - A modified Adam’s clasp This clasp was developed for use with magnetic activator device. The upper and lower plates, with incorporated magnets, of the appliance exert attracting or repelling force of about 600 gm. ${ }^{[3]} \mathrm{A} 2 \mathrm{~mm}$ loop on each side of arrowhead is given in the Adam's clasp.

\section{Delta clasp}

This clasp was designed by William J. Clark. This clasp is similar to Adam's clasp in principle. It engages interdental undercuts.

Adjustment: -hold retentive loop and twist inwards.

-bending towards interdental undercut as it emerges from acrylic.

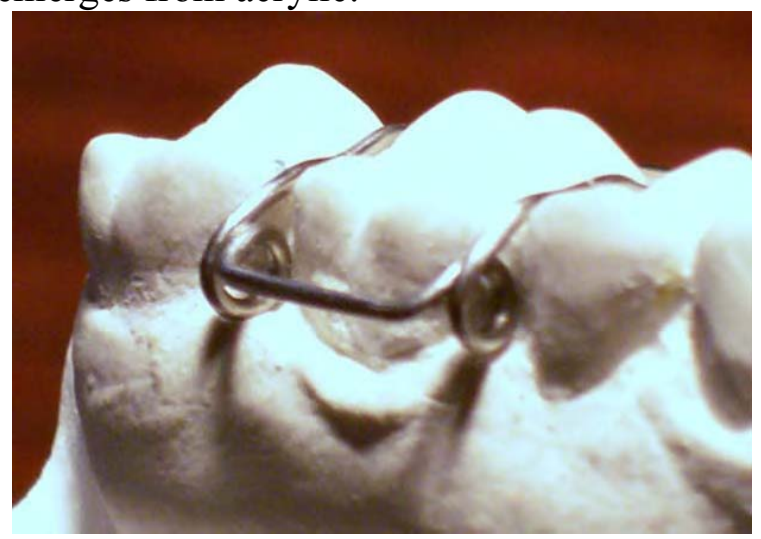

Fig. Delta clasp

\section{Southend clasp}

This clasp was named as southend clasp because it was developed by Mr. DiBiase and Mr. Leavis of department of orthodontics, Southend hospital and was used at Bristol Hospital. It provides retention in the anterior region. The wire is adapted along the cervical margin of both the central incisors. The distal end of the wire crosses over the occlusal embrasures and end as retentive arms on the palatal side.

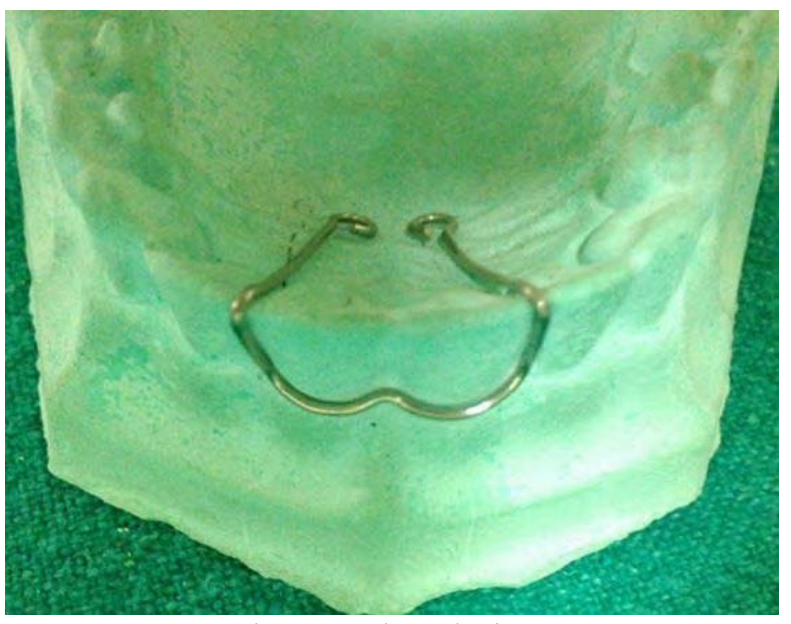

Fig. Southend clasp 
Advantages:-

- Better patient compliance

- Suitable for rotated and spaced incisors.

\section{Triangular Clasp}

It has a small triangular shape that engages the proximal undercut of two adjacent teeth. It provides excellent retention. It doesn't cause irritation of gingiva. It is used when additional retention is required.

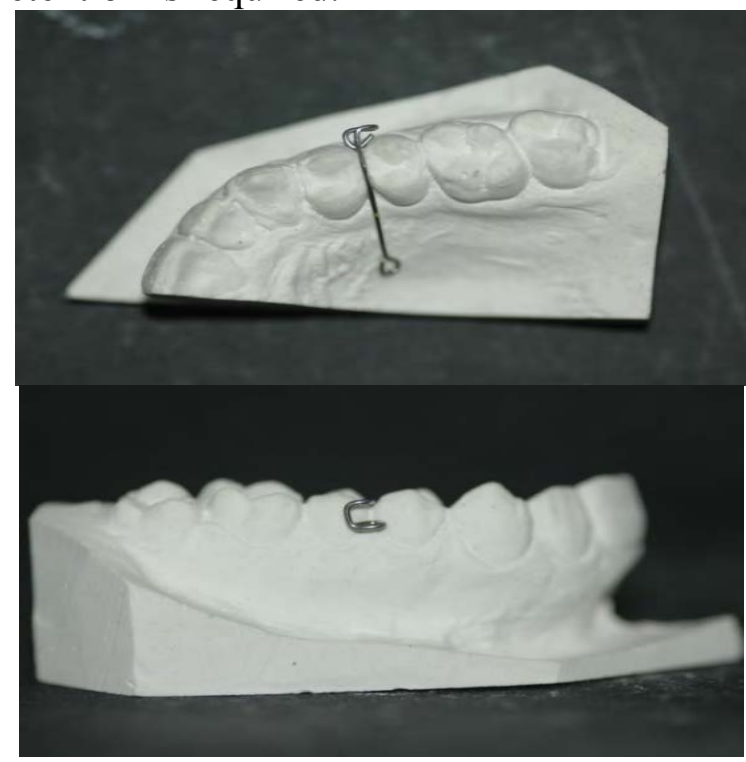

Fig. Triangular clasp

\section{Ball End Clasp}

This clasp is also known as Scheau anchor clasp. This clasp has a ball at the end which engages the proximal undercut between two adjacent teeth (interdental area). Preformed wires having a ball at the end are used for making this clasp. The ball can also be made using silver solder. This clasp is used whenever additional retention is required.

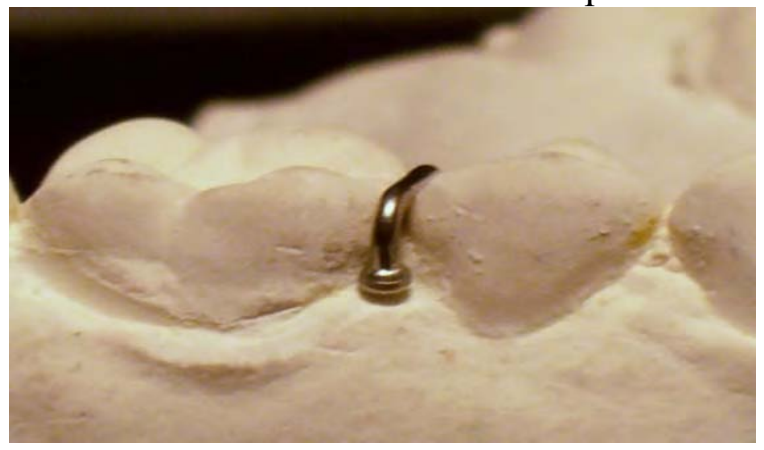

Fig. Ball end clasp

\section{Double Ball end Clasp}

This clasp includes a stem embedded into and extending from the acrylic portion of the appliance. Two ball clasps extend from the stem and are laterally spaced apart from one another. Each ball clasp has an elongated flexible member and an enlarged exposed end. A bridge segment extends laterally between the flexible members of the first and second ball clasps. ${ }^{[6]}$ This clasp does not exert any wedging force in the interdental embrasure like the single ball clasp. This clasp provides better retention.
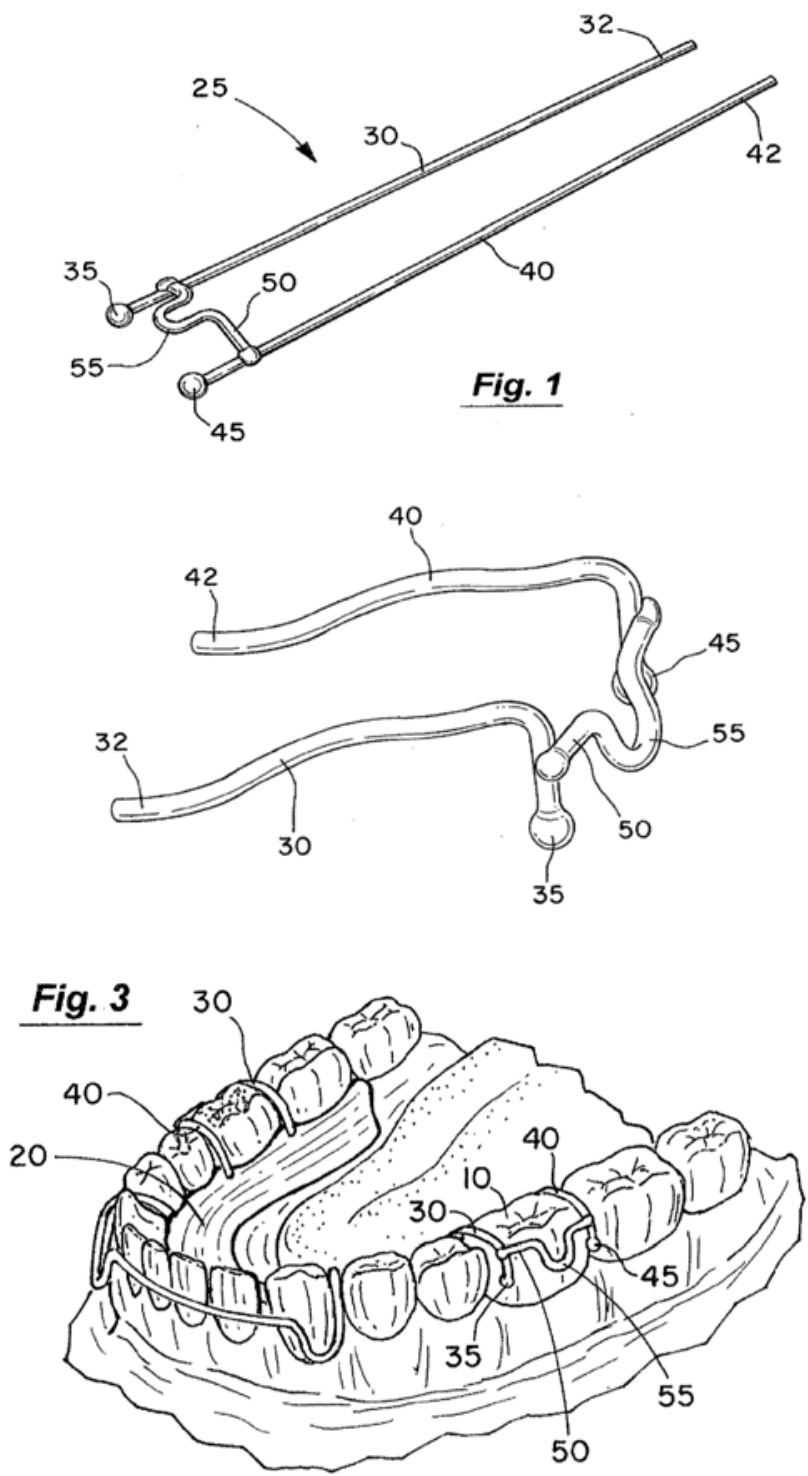

Fig. Double boule end clasp 


\section{Schwarz Clasp}

It is said to be predecessor of Adam's clasp. This clasp has a number of arrowheads that engage the inter-proximal undercuts of posterior teeth.

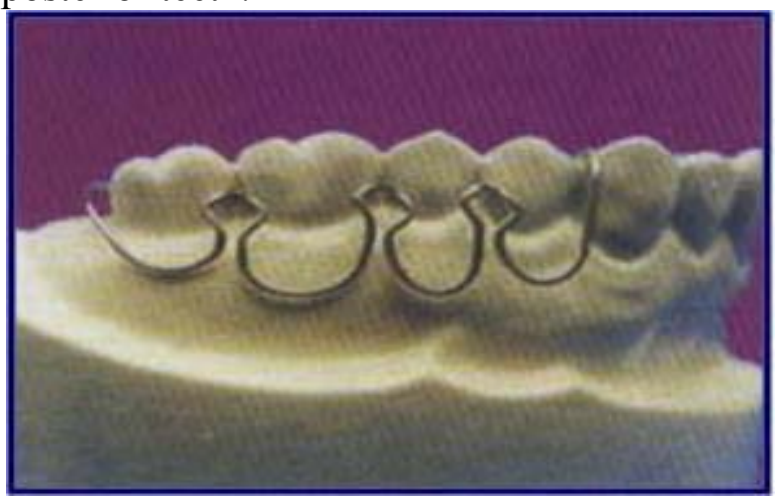

Fig. Schwarz clasp

This clasp is not routinely used because:-

- It needs special arrowhead forming pliers.

- It occupies a large amount of space in the buccal vestibule.

- The arrowheads can injure the interdental soft tissues.

- It is difficult and time consuming to fabricate.

\section{Crozat Clasp}

This clasp was suggested by Crozat in 1920. It is modification of Jackson's clasp. An additional piece of wire is soldered to the Jackson's clasp which engages into the mesial and distal proximal undercuts. Thus, it provides better retention than the Full clasp. ${ }^{[9]}$

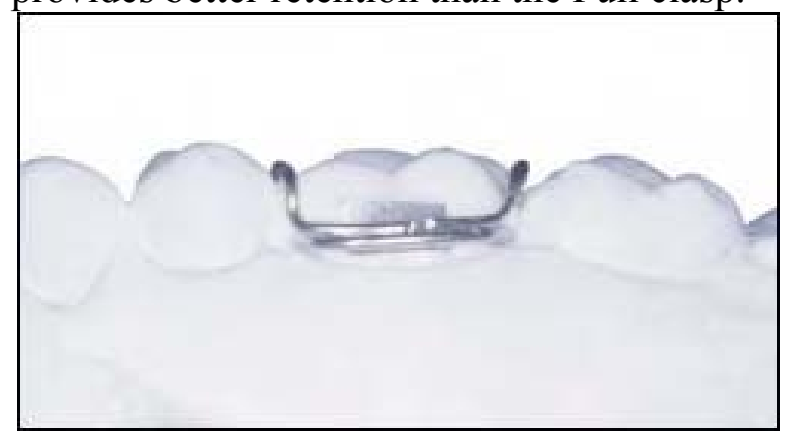

Fig. Crozat clasp

\section{Duyzing Clasp}

This clasp has two wires emerging from the plate that cross the occlusion over the anterior and posterior contact point of the tooth clasped. Each wire then goes above the greatest circumference of the tooth to the middle of the tooth and again back below using undercuts. This clasp is used to engage the buccal undercuts of molars.If the situation demands, only half of the clasp can also be made. ${ }^{[5]}$

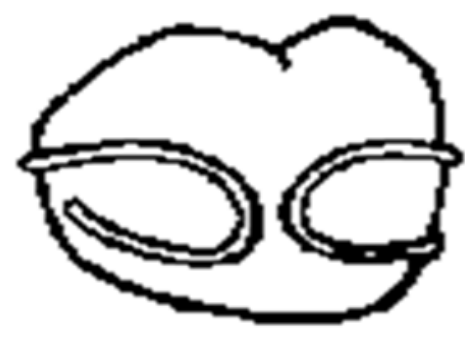

Fig. Duyzing's clasp ${ }^{[12]}$

\section{Eyelet Clasp}

This clasp can be constructed as a single eyelet or continuous eyelet clasp. ${ }^{[5]}$ An eyelet is made using a Young loop forming plier. Eyelets are placed in the embrasure. Three to four eyelets can be made depending upon the retention requirement. The size of the eyelet depends on the width of the interdental area of both anchor teeth. ${ }^{[9]}$
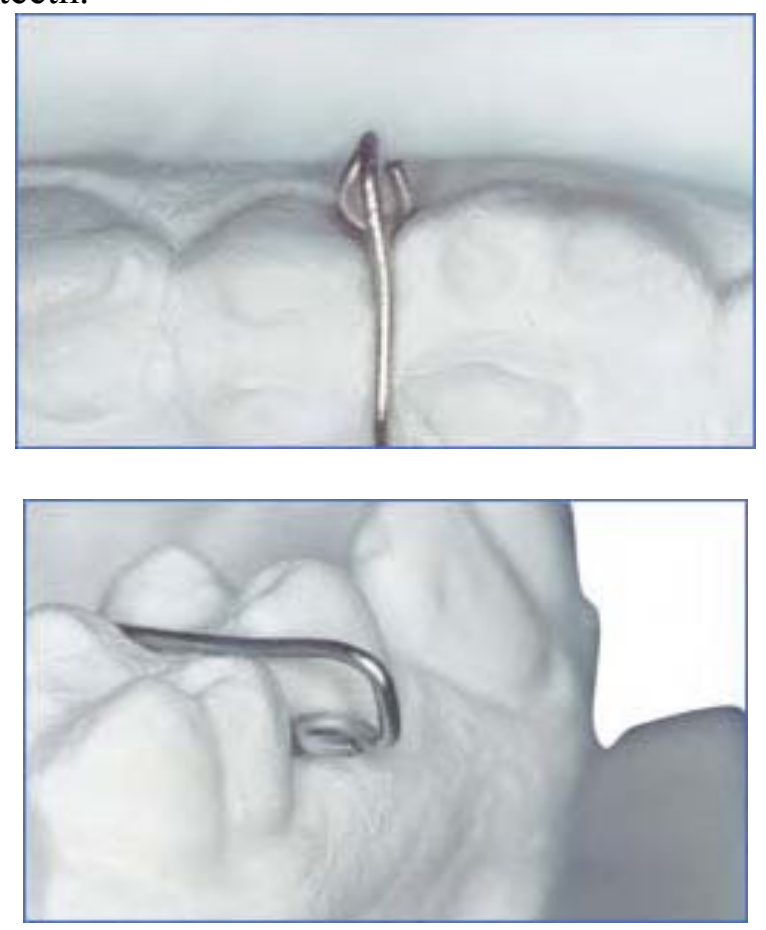

Fig. Eyelet clasp 


\section{Plint clasp}

Plint clasp is also known as 'Fly Over Clasp'. [11] Plint clasp are useful when using a removable appliance in combination with a fixed appliance. These clasps are constructed using $0.7 \mathrm{~mm}$ stainless steel wire. ${ }^{[4]}$ This clasp is used to engage under the tube assembly on a molar band. ${ }^{[10]}$ Adjustment: - by moving the clasp under the molar tube.

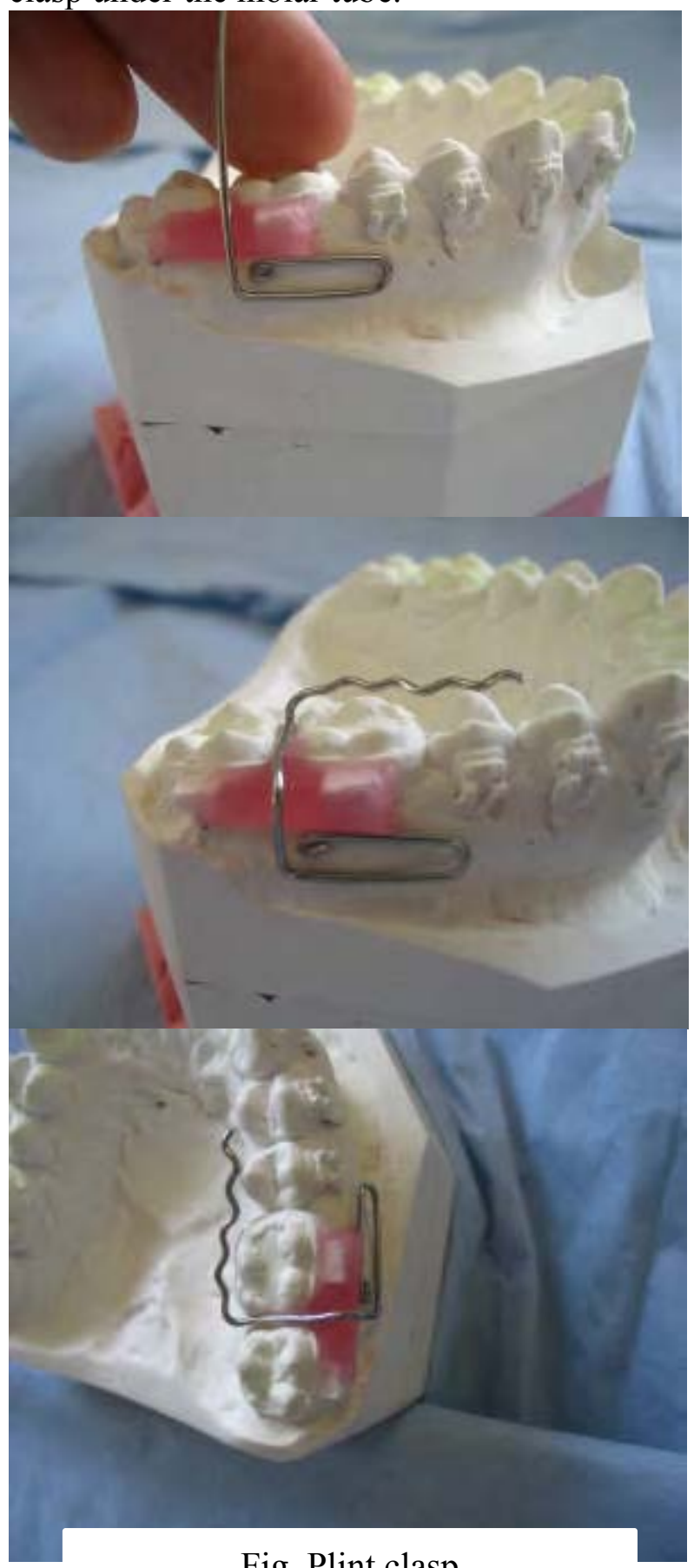

Fig. Plint clasp

\section{Visick Clasp}

This clasp was given by H C Visick. This clasp is used on palatal side for active retention accompanying the base plate and molar clasp on buccal side. It is made using $0.7 \mathrm{~mm}$ stainless steel wire. ${ }^{[3]}$ Retention is increased with this clasp because both the buccal and palatal surfaces are engaged. ${ }^{[3]}$

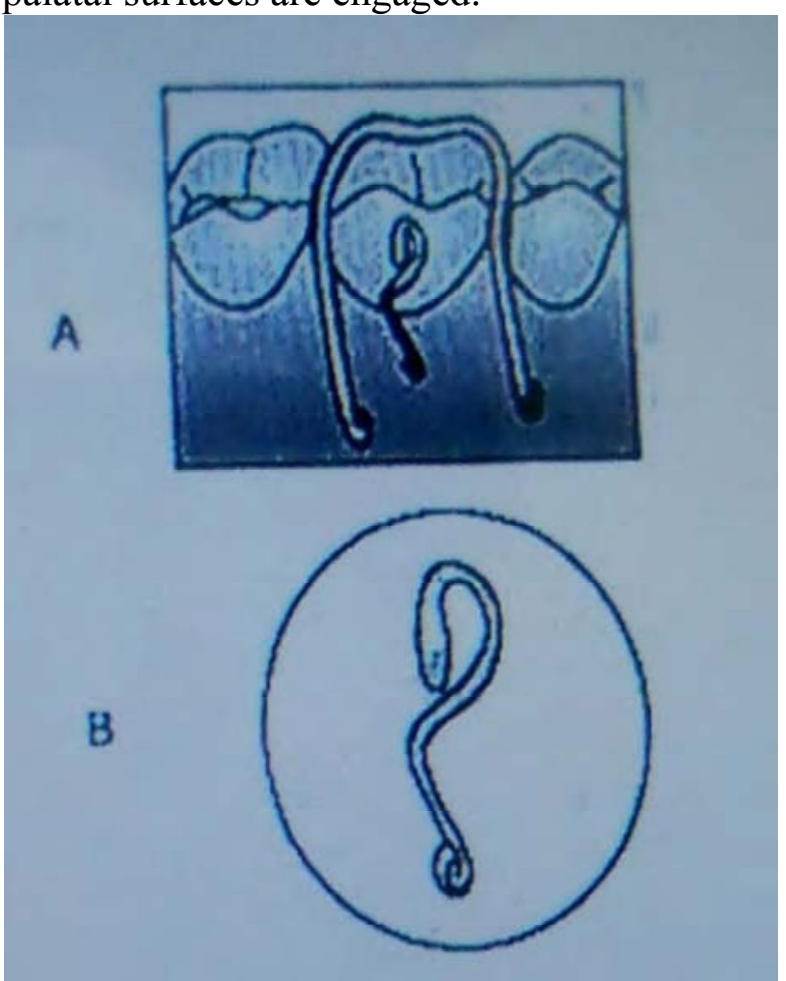

Fig. A. Visick clasp in place along with Jackson's clasp;

Fig. B. Close up view of Visick clasp. ${ }^{[12]}$

\section{References:}

1. Bhalaji S I; Orthodontics- The art and science, $4^{\text {th }}$ edition, Arya (Medi) publishing house, New Delhi; 2009, page 298-304.

2. Adams, C P; The design, construction and use of removable orthodontic appliances, $6^{\text {th }}$ edition, Varghese publishing house, Bombay; 1990, page 11.

3. Lohakare S S; Orthodontic Removable Appliances, $1^{\text {st }}$ edition, Jaypee Brothers Medical Publishers (P) Ltd, New Delhi; 2008, page 55-62.

4. Martyn T C, Andrew T DiBiase; Handbook of Orthodontics, $1^{\text {st }}$ edition, Mosby Elsevier, 2010, page -213 . 
5. Rani M S, Removable Orthodontic Appliances design, construction, application and management; $1^{\text {st }}$ edition, 1997, All India Publishers and Distributers, Chennai, 1997, page 40-41.

6. Donal $\mathbf{P}$ Inman, Clasp for Removable Dental Appliances, pub no. - US 2008/0057457/A1; pub date - March 6, 2008.

7. http://ebookbrowse.com/principles-of-removableappliances-bw-pdf-d321047256

8. http://www.e-moh.com/vb/t115325/

9. http://www.o-atlas.de/eng/kapitel1_41.php; http://www.o-atlas.de/eng/kapitel1_44.php; http://www.o-atlas.de/eng/kapitel1_45.php; http://www.o-atlas.de/eng/kapitel6_191.php; http://www.o-atlas.de/eng/kapitel1_47.php;

10. http://fx.damasgate.com/removable-appliances/

11. http://universal-dentaltechniques.com/Web_page/Fly_Over_Clasp.html

12. Shridhar Premkumar; Orthodontics: Prep manual for undergraduates, Orthodontic appliances, Removable appliances, page 303-304; 2008 Elsevier.

Correspondence Address: Dr Mustapha Mansuri, E-mail: mustapha.mansuri@bpkihs.edu; mansurimustapha@gmail.com Phone: +977- 9803504255; 9841502419. 